\title{
Los efectos de la homologación de la transacción extrajudicial Análisis Casatorio.
}

Casación № 3435-2009-Arequipa

Pérez Solf, Yván*

\section{SUMARIO}

I. Introducción; II. Analizando las implicancias jurídicas de la transacción en el ordenamiento peruano; III. La transacción extrajudicial vs. La transacción judicial; IV. La homologación y sus efectos como cosa juzgada; V. Análisis casatorio: Casación № 34352009-Arequipa; VI. Conclusiones; VII. Referencias Bibliográficas

\section{INTRODUCCIÓN}

La transacción es un medio de solución de conflictos, mediante el cual las partes autocomponen sus diferencias, a través de concesiones recíprocas, con ahorro de tiempo y gastos, aliviando la carga procesal. Pese a ello y a la notoria relevancia social y jurídica que dicha institución posee, se advierte que no se ha comprendido su verdadero contenido. Razón por la cual, a continuación se realizará un breve análisis acerca de las implicancias jurídicas que posee en nuestro ordenamiento. Posteriormente, se comparará la transacción extrajudicial y judicial, junto con la homologación y los efectos como cosa juzgada. Por último, se realizará un análisis sobre la Casación № 3435-2009-Arequipa.

\section{ANALIZANDO LAS IMPLICANCIAS JURÍDICAS DE LA TRANSACCIÓN EN EL ORDENAMIENTO PERUANO}

La Real Academia de la Lengua Española define el término transacción como aquel trato, convenio o negocio. En otras palabras, como aquella acción y efecto de transigir ${ }^{1}$. Este último término es entendido como "consentir en parte con lo que no se cree justo, razonable o verdadero, a fin de acabar con una diferencia ${ }^{2}$ ”. Sin embargo, otra acepción lo define como

\footnotetext{
* Docente de la Facultad de Derecho. Universidad Católica Santo Toribio de Mogrovejo.

${ }^{1}$ Cfr. REAL ACADEMIA ESPAÑOLA. Diccionario de la Lengua Española - Tomo 18: Tabulador Ultrapuertos, Q.W. Editores S.A.C., 2005, p. 1500.

${ }^{2}$ REAL ACADEMIA ESPAÑOLA. Diccionario de la Lengua Española - Tomo 18: Tabulador Ultrapuertos, Q.W. Editores S.A.C., 2005, p. 1502.
} 
“ajustar algún punto dudoso o litigioso, conviniendo las parte voluntariamente en algún medio que componga y parta la diferencia de la disputa" ${ }^{3 "}$.

Como es lógico las definiciones brindadas por dicha enciclopedia son correctas. No obstante, la que se adecúa mejor al concepto de transacción en nuestro ordenamiento jurídico es la segunda. Toda vez que, consideramos a la transacción como un medio eficaz de solucionar conflictos de manera sencilla, mediante la cual, las partes autocomponen sus diferencias, a través de concesiones recíprocas, con ahorro de tiempo y gastos, aliviando la carga procesal. En otras palabras, es uno de los mecanismos ágiles de solución de conflictos, cuya finalidad está orientada a resolver un conflicto por las propias partes mediante concesiones recíprocas [autocomposición]. Todo ello en virtud, a que siendo las partes quienes conocen mejor la situación controvertida, son ellas las llamadas a dar solución al conflicto, resultando más beneficioso y productivo, que la intervención de un tercero que no conoce de los hechos que suscitaron la discusión y que, podría dar una solución que beneficie sólo a una de las partes, perjudicando o desfavoreciendo a la otra ${ }^{4}$.

El Código Civil peruano regula esta institución jurídica en su artículo $1302^{\circ}$, estipulando que: "Por la transacción las partes, haciéndose concesiones, deciden sobre algún asunto dudoso o litigioso, evitando el pleito que podría promoverse o finalizando el que está iniciado. Con las concesiones recíprocas, también se pueden crear, regular, modificar o extinguir relaciones diversas de aquellas que han constituidos objeto de controversia entre las partes. La transacción tiene valor de cosa juzgada". Del citado artículo se pueden extraer las características propias de esta figura jurídica: acto jurídico bilateral, relación jurídica preexistencial, asunto dudoso, asunto litigioso, existencia de concesiones recíprocas y su principal característica, es decir, ostentar el valor de cosa juzgada, no siendo exactamente una cosa juzgada que es exclusividad del órgano jurisdiccional

A continuación, se analizarán - de manera sucinta - las características propias de la transacción. En primer lugar, el mencionado artículo señala que la transacción se realiza entre “las partes". Por lo tanto, es un acto jurídico bilateral, al necesitar el acuerdo de voluntades

\footnotetext{
${ }^{3}$ REAL ACADEMIA ESPAÑOLA. Diccionario de la Lengua Española - Tomo 18: TabuladorUltrapuertos, Q.W. Editores S.A.C., 2005, p. 1502.

${ }^{4}$ Cfr. CASTILLO FREYRE, Mario \& OSTERLING PARODI, Felipe. Tratado de las Obligaciones, Fondo Editorial, Lima, 2001, p. 444.
} 
que consagre la intención de las partes para componer el conflicto [animus transigendi $]^{5}$. Por otro lado, debe versar sobre asuntos dudosos o litigiosos, siendo el primer requisito o elemento esencial de la transacción, siendo éstos consecuencia de una relación jurídica patrimonial preexistente $^{6}$. Debe entenderse por asunto dudoso ${ }^{7}$ cuando las partes subjetivamente consideran que son inciertos los derechos y obligaciones que han adquirido o que adquirirán, incertidumbre que puede deberse al desacuerdo entre las partes preexistente a la transacción; a la particular opinión que tengan sobre los hechos o sobre el derecho; a su desconfianza en el poder judicial o en el arbitraje; a su temor a los costos que conlleva un proceso judicial; entre otros factores. Las causas pueden ser muy diversas, ante ello, las partes deciden no acudir ante la instancia judicial y dar inicio a una transacción extrajudicial, de modo que, cuando nuestro Código Civil hace mención a un asunto dudoso, señala la inexistencia de proceso ${ }^{8}$. Mientras que por asunto litigioso se entiende aquel asunto que es materia de un proceso judicial, bastando para ello la interposición de la demanda, ya que con ella se da inicio al proceso. Con la transacción se pondría fin al proceso judicial o arbitral en curso. De igual manera, otra característica de la transacción es la existencia de concesiones recíprocas, ya que implica que exista un intercambio de sacrificios, que cada parte reciba como contraprestación el sacrificio de la otra; en otras palabras, que ambas cedan mutuamente en algo sus pretensiones originarias con el propósito de dar fin a la controversia. Por último, se encuentra el valor que tiene la transacción como cosa juzgada ${ }^{9}$, el cual tiene como propósito brindar estabilidad y dar seguridad jurídica.

${ }^{5}$ Cfr. SUÁREZ GAMARRA, Raúl. Código Civil comentado - Tomo VI: Tomo de Obligaciones, Gaceta Jurídica, Lima, 2007, p. 583.

${ }^{6}$ Cfr. TORRES VÁSQUEZ, Aníbal. "Sobre la transacción extrajudicial" en Revista Actualidad Jurídica Tomo 170, Lima, enero 2008, p. 21.

${ }^{7}$ Los juristas Mario Castillo y Felipe Osterling señalan que: "Basta que el asunto sea dudoso, es decir que no exista litigio, para que las partes por medio de la transacción puedan prevenir el proceso", siendo ésta considera como transacción dudosa o extrajudicial. VER en CASTILLO FREYRE, Mario \& OSTERLING PARODI, Felipe. Tratado de las Obligaciones, Fondo Editorial, Lima, 2001, p. 455.

${ }^{8}$ Cfr. SUÁREZ GAMARRA, Raúl. Código Civil comentado - Tomo VI: Tomo de Obligaciones, Gaceta Jurídica, Lima, 2007, p. 587.

${ }^{9}$ Según el artículo $123^{\circ}$ del Código Procesal Civil:

"Una resolución adquiere la autoridad de cosa juzgada cuando:

1. No proceden contra ella otros medios impugnatorios que los ya resueltos; o

2. Las partes renuncian expresamente a interponer medios impugnatorios o dejan transcurrir los plazos sin formularlos.

La cosa juzgada sólo alcanza a las partes y a quienes de ellas deriven sus derechos. Sin embargo, se pueden extender a los terceros cuyos derechos dependen los de las partes, si hubieran sido citados con la demanda.

La resolución que adquiere la autoridad de cosa juzgada es inmutable, sin perjuicio de lo dispuesto en los artículo $178^{\circ}$ y $407^{\circ}$. 
Habiendo hecho mención a las principales características de la figura jurídica bajo análisis, conviene señalar cuáles son los efectos que ésta produce; al respecto, la mayoría doctrinaria afirma que i) es obligatoria o vinculante, debido a que crea para las partes una regla a la cual deberán someterse por contener ésta un carácter contratual; ii) es extintiva, por lo que las partes no podrán hacer valer luego los derechos renunciados a través de este acto, si así lo hicieran dicha pretensión será rechazada; iii) su efecto es declarativo, significa que cuando uno de los contratantes reconoce el derecho del otro, no significa que se lo está transmitiendo, sino que este derecho ha existido desde antes y directamente en cabeza de quien lo tiene luego de la transacción; y, iv) posee el valor de cosa juzgada; condición que le ha sido otorgada por el legislador y que posteriormente será analizada ${ }^{10}$.

Por lo tanto, se concluye que para nuestro ordenamiento jurídico nacional la transacción es un acto de naturaleza patrimonial, por el cual las partes, haciendo uso de su autonomía de voluntad, deciden sobre un asunto dudoso o litigioso, haciéndose concesiones recíprocas. Al respecto, la Corte Suprema de Justicia ha señala que "a nivel formal, al ser un contrato, apunta a zanjar cuestiones ya existentes entre las partes, es decir a extinguir relaciones jurídicas existentes que se encuentran en controversia. Por ello, su ubicación es más clara dentro de los medios extintivos de las obligaciones. En cuanto a nivel de fondo, lo que subyace en el corazón de esta figura se centra en la búsqueda de la paz y armonía"11.

\section{LA TRANSACCIÓN EXTRAJUDICIAL VS. LA TRANSACCIÓN JUDICIAL}

Después del análisis sobre las características fundamentales de la transacción se vislumbra que nuestro legislador hace una diferencia entre asunto dudoso y litigioso. Por ello, la doctrina es unánime e indica con total claridad que cuando se extingue una obligación dudosa - aquella susceptible de originar un litigio, pero éste se previene - nos encontramos frente a una transacción extrajudicial. Por el contrario, cuando se extingue una obligación litigiosa - aquella discrepancia entre las partes que ha sido sometida a instancia judicial - nos encontramos frente a una transacción judicial.

\footnotetext{
${ }^{10}$ Cfr. PRIMER PLENO CASATORIO CIVIL: CASACIÓN N ${ }^{\circ}$ 1465-2007-CAJAMARCA. 2009 [ubicado 24.X 2011]. Obtenido en http://www.justiciaviva.org.pe/nuevos/2008/abril/24/sentencia.pdf, pp. 27-28.

${ }^{11}$ Cfr. PRIMER PLENO CASATORIO CIVIL: CASACIÓN No 1465-2007-CAJAMARCA. 2009 [ubicado 24.X 2011]. Obtenido en http://www.justiciaviva.org.pe/nuevos/2008/abril/24/sentencia.pdf, pp. 24-25.
} 
La transacción extrajudicial, como ya fue mencionado, es aquella que se realiza sin mediar proceso, ello se traduce en que se origina antes del litigio judicial o fuera de este, precisamente, su importancia radica en evitar el pleito a promoverse o solucionarse fuera del Orgaz jurisdiccional. La transacción que se en el pleito no constituye una transacción extrajudicial, pues la litis ya ha sido trabada, configurando una transacción judicial, caso distinto es cuando las partes abandonan el proceso y transan fuera del él, el eje central para determinar si una transacción es judicial o extrajudicial radica en determinar cuál de ellas contiene un acto jurisdiccional.

Al respecto, Roberto Valdés Sánchez sostiene que la transacción extrajudicial puede presentarse cuando las partes se encuentra frente a un conflicto de intereses que se sustenta en una situación de duda sobre distintos aspectos de la relación, la misma que puede provenir de una de las partes o de ambas; asimismo, indica que esta duda o inseguridad puede ser meramente subjetiva, pero que encierra razonables elementos de incertidumbre que impiden que la relación jurídica acontezca con normalidad ${ }^{12}$.

La transacción judicial es aquella que se lleva en el interior de un proceso judicial, para ponerle fin, ello implica que la controversia ha sido puesta a disposición del órgano jurisdiccional correspondiente, y antes de dictar sentencia, las partes efectúan una transacción que además deberá ser homologada por juez ${ }^{1314151617}$. Cabe precisar que, el artículo $334^{\circ}$ del Código Procesal Civil peruano señala que este tipo de transacción se puede llevar a cabo "en cualquier estado del proceso [...] incluso durante el trámite del recurso de casación y aun cuando la causa esté al voto o en discordia".

Es importante señalar las diferencias existentes entre ambos tipos de transacción - extrajudicial y judicial. Sin embargo, parte de la doctrina suele confundirla, tal es el caso del jurista Hilmer Zegarra quien manifiesta que "la transacción judicial es la que se celebra dentro del proceso y

${ }^{12}$ Cfr. PRIMER PLENO CASATORIO CIVIL: CASACIÓN No 1465-2007-CAJAMARCA. 2009 [ubicado 24.X 2011]. Obtenido en http://www.justiciaviva.org.pe/nuevos/2008/abril/24/sentencia.pdf, p. 102.

${ }^{13}$ Cfr. ALBALADEJO, Manuel. Derecho Civil - Volumen II: Derecho d Obligaciones, Editorial Bosh, Barcelona, 1993, p. 382.

${ }^{14}$ Cfr. CASTILLO FREYRE, Mario \& OSTERLING PARODI, Felipe. Tratado de las Obligaciones, Fondo Editorial, Lima, 2001, p. 474.

${ }^{15}$ Cfr. HINOSTROZA MINGUEZ, Alberto. Formas especiales de conclusión del proceso, Gaceta Jurídica, Lima, 2002, p. 146.

${ }^{16}$ Cfr. PUIG BRUTAU, José. Compendio de Derecho Civil - Volumen II, Editorial Bosh, Barcelona, 2002, p. 579.

${ }^{17}$ Cfr. ZUMAETA MUÑOZ, Pedro. Temas de la teoría del proceso, Jurista Editores, Lima, 2004, p. 165. 
en presencia del juez, en cambio la extrajudicial es la que existiendo proceso abierto, es celebrada fuera de este, en consecuencia al ser celebrada esta última en documento privado ${ }^{18 \%}$.

\section{LA HOMOLOGACIÓN Y SUS EFECTOS COMO COSA JUZGADA}

Según la Enciclopedia Salvat, el término homologar debe interpretarse como aquella confirmación por parte del juez sobre ciertos actos y convenios de las partes para hacerlos más firmes y solemnes ${ }^{19}$. En este sentido, la homologación de la transacción significa la aprobación, confirmación o solemnización de lo establecido por las partes a través de la transacción, una vez que el juez ha observado que se cumplan determinados requisitos legales tales como:

a. Que la transacción contenga concesiones recíprocas.

b. Que verse sobre derechos patrimoniales.

c. No afecte el orden público ni las buenas costumbres [artículo $337^{\circ}$ primer párrafo del $\mathrm{CPC}]$.

La homologación no es una sentencia, (es un auto final, sin decisión del juez si no de las partes) es una aprobación, (en buena cuenta se impone el sistema autocompositivo de solución de conflictos de partes frente al heterocompositivo de juez), cuando decide el juez solo hace mediante una sentencia, aunque ambas actividades son distintas, ambos son actos jurisdiccionales que la ley le ha otorgado el mérito de cosa juzgada.

Respecto a la transacción judicial, nuestro legislador ha convenido en que ésta debe ser homologada por el juez de la causa; tal y como ha sido estipulado en el artículo $337^{\circ}$ del Código Procesal Civil, el cual señala que "el juez aprueba la transacción siempre que contenga concesiones recíprocas, verse sobre derechos patrimoniales y no afecte el orden público o las buenas costumbres, y declara concluido el proceso si alcanza a la totalidad de las pretensiones propuestas. Queda sin efecto toda decisión sobre el fondo que no se encuentre firme. La transacción que pone fin al proceso tiene la autoridad de cosa juzgada. El incumplimiento de la transacción no autoriza al perjudicado a solicitar la resolución de ésta $[\ldots]$ '.

${ }^{18}$ ZEGARRA ESCALANTE, Hilmer. Formas alternativas de concluir un proceso civil, Editorial Marsol, Lima, 2006, p. 155.

${ }^{19}$ Cfr. SALVAT EDITORES. La Enciclopedia - Volumen 10: Guadalupe - Inculpable, Salvat Editores, Madrid, 2004, p. 7732. 
Es necesario recalcar que en este punto, es sujeto de debate el considerar si es que la transacción extrajudicial tiene o no la calidad de cosa juzgada que sí le es otorgada a la transacción judicial; al respecto, es relevante señalar que según el análisis realizado por la Corte Suprema de Justicia del Perú, la mayoría doctrinaria sostiene que la transacción como contrato que es (acto juridico), no tiene la capacidad de producir los efectos de cosa juzgada y que únicamente este efecto recae sobre aquella transacción que haya sido homologada por el juez $^{20}$. De allí que, la transacción judicial se equipara a una sentencia y por ende tendrá los mismos efectos de aquella, entre ellos el de fuerza ejecutoria, el mismo que pone fin a cualquier intención que tengan las partes de revivir el derecho litigioso al que la transacción homologada puso fin; es únicamente una transacción de esta naturaleza la que se equipara a la cosa juzgada, pues cumple con el requisito de inmutabilidad ${ }^{21}$.

\section{ANÁLISIS CASATORIO: CASACIÓN Nº 3435-2009-AREQUIPA}

La Sala Civil Permanente de la Corte Suprema de Justicia ha resuelto el recurso de casación interpuesto por la Sucesión de Juan Crisóstomo Torrico Gonzáles contra la sentencia de primera instancia y la sentencia materia del recurso de apelación, debido a que ambas declararon improcedente la demanda de nulidad de acto jurídico propuesta por la mencionada sucesión, toda vez que consideraron se debía declarar la nulidad de la transacción extrajudicial celebrada entre la apoderada del causante Juan Crisóstomo Torrico Gonzáles con los demandantes.

Es menester indicar que la Sala declaró procedente el recurso de casación, por la infracción normativa procesal de los artículos $178^{\circ}$ y $337^{\circ}$ del Código Procesal Civil; a pesar que el mencionado artículo $178^{\circ}$ señala que se declarará la nulidad de un acto jurídico en caso exista fraude o colusión, la demandante señala que el recurso se interpone por causales distintas a las precisadas en el referido artículo, toda vez que lo que ha ocurrido en el caso sub-litis es incumplimiento de los requisitos formales establecidos en nuestra legislación, los mismos que son sancionados con nulidad.

\footnotetext{
${ }^{20}$ Cfr. PRIMER PLENO CASATORIO CIVIL: CASACIÓN No 1465-2007-CAJAMARCA. 2009 [ubicado 24.X 2011]. Obtenido en http://www.justiciaviva.org.pe/nuevos/2008/abril/24/sentencia.pdf, p. 33.

${ }^{21}$ Cfr. PRIMER PLENO CASATORIO CIVIL: CASACIÓN No 1465-2007-CAJAMARCA. 2009 [ubicado 24.X 2011]. Obtenido en http://www.justiciaviva.org.pe/nuevos/2008/abril/24/sentencia.pdf, p. 105.
} 
La Sala reconoce que, si bien es cierto, la transacción adquiere el carácter de cosa juzgada [establecido en el último párrafo del artículo $1302^{\circ}$ del Código Civil], ello no quiere decir que no existan supuestos en los cuales la transacción pueda ser declara nula, anulable y resoluble [en virtud al artículo $1308^{\circ}$ del Código Civil]. En consecuencia, afirma que no es jurídicamente imposible declarar la nulidad de una transacción, pues en efecto el artículo $1308^{\circ}$ en concordancia con los artículos $219^{\circ}, 220^{\circ}, 221^{\circ}, 230^{\circ}, 231^{\circ}$ y $232^{\circ}$ del Código Civil señalan que todo acto jurídico puede ser nulo o anulable.

En el caso de autos, se solicitó que se declare la nulidad por infracción normativa procesal, a lo cual la Sala declaró que ésta se presenta cuando se afectan derechos procesales, la misma que es sancionada con nulidad procesal; es necesario indicar que éste es simplemente un estado de anormalidad del acto procesal, el cual no debe afectar el debido proceso, ya que el vicio puede ser subsanable, ya sea por convalidación o simplemente porque el acto ha cumplido con su finalidad. En estos casos, es competencia de la Suprema Sala verificar si se han vulnerado aquellas normas que establecen un determinado comportamiento procesal, de ser así se debe disponer la anulación del acto jurídico cuestionado.

En el presente caso, la Sala afirma que se debe evaluar la impugnación de la transacción extrajudicial homologada por el juez, en virtud de los artículos $334^{\circ}, 335^{\circ}$ y $337^{\circ}$ del Código Procesal Civil, impugnación que corresponde realizarse tomando en consideración lo estipulado en el artículo $178^{\circ}$ del referido cuerpo legal y al no existir fundamentos para declarar el acto jurídico como nulo por fraude o colusión existe en el presente caso, corresponde declarar infundado el recurso de casación.

\section{CONCLUSIONES}

La naturaleza jurídica de la transacción es contractual, en virtud a que constituye una manifestación de voluntad destinada a crear, regular, modificar o extinguir relaciones jurídicas, de tal forma que la transacción es un contrato con la particularidad de ostentar el valor de cosa juzgada; precisamente por esta naturaleza la transacción tiene que observar los elementos de validez del acto jurídico. La diferencia entre la transacción judicial y extrajudicial radica en la homologación de la transacción, y en que ésta sólo es exigible a la transacción judicial, ello en virtud, a su naturaleza litigiosa, dicha aprobación dada por el juez es lo que le otorga la calidad de cosa juzgada. 
Otra diferencia importante radica en que si bien la transacción judicial ostenta el valor de cosa juzgada material, en virtud a la homologación del juez, ello no significa, que no se pueda demandar su nulidad; de tal manera que esta institución jurídica haya sus causas de invalidez en los supuestos relacionados a los actos jurídicos y contratos [en razón a su naturaleza contractual].

Para concluir, el valor de cosa juzgada que el legislador le ha investido a la transacción es aplicable sólo a la transacción judicial. Los efectos de la cosa juzgada solo podrían asimilarse a una transacción extrajudicial si el origen de esta solución es dada por un conflicto suscrita o derivada de un convenio o contrato entre partes que los obliga a solucionar su controversia, es decir no tendrá efectos de cosa juzgada un contrato de compra venta, pero si tendrá efectos de cosa juzgada si a raíz de ese contrato se incumplió la entrega del bien o el cumplimiento de la obligación y se soluciono por transacción extrajudicial, con lo cual se pone fin al conflicto, ya no existiría mas discusión sobre el tema y tendría los mismos efectos, sin ser cosa juzgada.

Hay que señalar que en la solución de los conflictos (Autocompositiva) resulta siempre mas importante que la propia administración de justicia a nivel heterocompositivo, toda vez que la transacción en buena cuenta es una forma mas eficaz de satisfacción de intereses de ambas partes, donde ambos pierden y ganan (concesiones reciprocas), y no como en el órgano jurisdiccional donde solo uno tendrá la razón, al declarar FUNDADA o INFUNDADA una demanda.

\section{REFERENCIAS BIBLIOGRÁFICAS}

ALBALADEJO, Manuel. Derecho Civil - Volumen II: Derecho de Obligaciones, Editorial Bosh, Barcelona, 1993.

$\checkmark$ CASTILLO FREYRE, Mario \& OSTERLING PARODI, Felipe. Tratado de las Obligaciones, Fondo Editorial, Lima, 2001.

HINOSTROZA MINGUEZ, Alberto. Formas especiales de conclusión del proceso, Gaceta Jurídica, Lima, 2002. 
$\checkmark$ PRIMER PLENO CASATORIO CIVIL: CASACIÓN No 1465-2007-CAJAMARCA. 2009 [ubicado 24.X 2011].

Obtenido

en http://www.justiciaviva.org.pe/nuevos/2008/abril/24/sentencia.pdf

$\checkmark$ PUIG BRUTAU, José. Compendio de Derecho Civil - Volumen II, Editorial Bosh, Barcelona, 2002.

REAL ACADEMIA ESPAÑOLA. Diccionario de la Lengua Española - Tomo 18: Tabulador - Ultrapuertos, Q.W. Editores S.A.C., 2005.

SALVAT EDITORES. La Enciclopedia - Volumen 10: Guadalupe - Inculpable, Salvat Editores, Madrid, 2004.

SUÁREZ GAMARRA, Raúl. Código Civil comentado - Tomo VI: Tomo de Obligaciones, Gaceta Jurídica, Lima, 2007.

$\checkmark$ TORRES VÁSQUEZ, Aníbal. "Sobre la transacción extrajudicial” en Revista Actualidad Jurídica - Tomo 170, Lima, enero 2008.

ZEGARRA ESCALANTE, Hilmer. Formas alternativas de concluir un proceso civil, Editorial Marsol, Lima.

$\checkmark$ ZUMAETA MUÑOZ, Pedro. Temas de la teoría del proceso, Jurista Editores, Lima, 2004. 